\title{
LESSER SAPHENOUS VEIN ANEURYSM AND POPLITEAL VEIN ANEURYSM: REPORT OF TWO CASES AND REVIEW OF THE LITERATURE
}

\author{
Petr Drac ${ }^{\mathrm{a}}$, Petr Utikal ${ }^{\mathrm{a}}$, Martin Köcher ${ }^{\mathrm{b}}$, Marie Cerna ${ }^{\mathrm{b}}$, Jiri Kozak ${ }^{\mathrm{b}}$, Petr Bachleda ${ }^{\mathrm{a}}$
}

\author{
${ }^{a}$ Department of Surgery II, University Hospital Olomouc, Czech Republic \\ ${ }^{b}$ Department of Radiology, University Hospital Olomouc \\ e-mail : petr.drac@fnol.cz
}

Received: April 28, 2008; Accepted (with revision): October, 2009

Key words: Lesser saphenous vein aneurym/Popliteal vein aneurysm/Thrombembolism/Venous duplex imaging/Surgery

Background: During the last ten years we diagnosed two cases of venous aneurysm. The purpose of this report was to point out a certain risk of the thrombembolism of superficial venous aneurysms and to review our experience in the management of superficial and deep venous aneurysms.

Methods: The presentation and management of these lesions were reviewed and discussed together with other cases from available literature.

Results: In the first case an aneurysm of lesser saphenous vein with a possible threat of thrombembolism was revealed and surgically solved with saphena resection. Ten years after the surgery she is still symptom free. In the second case a small fusiforme popliteal vein aneurysm without any evidence of mural thrombus was diagnosed. The patient was treated conservatively with regular venous duplex imaging follow up. Two years later the disease has been stable.

Conclusions: Superficial venous aneurysms can have a certain risk of the thrombembolism. Since surgical therapy is very simple, it can be recommended in all cases. Nevertheless, trombembolism is more common in deep venous aneurysms, especially popliteal ones, in which surgical repair can be based on their pathological features and presentation or can be indicated in all cases.

\section{INTRODUCTION}

Primary venous aneurysms are rare and usually have no clinical significance. An important exception, however, is an aneurysm of the popliteal vein that can be a source for pulmonary embolism. There is therefore enough available literature concerning this topic. May and Nissel described first PVA yet in 1968 (ref. ${ }^{1}$ ). The most common and serious PVA complication, thrombosis and pulmonary emboli, was reported by Dahl et al. in 1976 (ref. ${ }^{2}$ ). Less attention has been paid to superficial venous aneurysms having thrombembolic complications less frequent ${ }^{3-5}$. Case 1. reported herein represents an interesting example of this pathology, being, in addition, very similar to popliteal vein aneurysm concerning both localization and threat of thrombembolism.

\section{CLINICAL EXAMPLE}

Case 1. A 48-year-old woman showed intermittent paresthesia of the right calf for several weaks. Her medical history included stripping of the right-sided greater saphenous vein two years before above mentioned complaints (previous venous duplex imaging was not performed) and left-sided chronic lumbo-ischial syndrome. She had no history of chest pain, dyspnea, or venous thrombosis. The general practitioner referred her to a neurologist who claimed the irritation of the sensitive branches of the tibial nerve. In order to exclude a local pathology in the right popliteal fossa, following investigations were done. An orthopedist used B-scan sonography which revealed a $2 \mathrm{~cm}$ wide cystic resistance adjacent to the nerve-vascular popliteal bundle and excluded a Baker's cyst and tumor. The patient was then referred to our vascular out-patient department. We considered a popliteal artery aneurysm first. The physical examination of the lower limbs was normal; the resistance was not palpable. Imagings of CTA and MRI were assessed to be a saccular aneurysm of the right popliteal vein, but venous duplex imaging performed before the above mentioned investigations revealed and the side view of ascending venography confirmed an aneurysm of the lesser saphenous vein close to the saphenopopliteal junction (Fig. 1-3). This unusual finding was the reason for utilizing of all the available imaging techniques. Venous duplex imaging of the contralateral extremity excluded similar pathology - only insignificant reflux of the great saphenous vein was found.

Venous duplex imaging showed, how dangerous the aneurysm was (Fig. 4). The insufficient valve of the saphenopopliteal junction enabled blood reflux into the aneurysm. Then the blood flow encountered on the contrary sufficient valve situated close beneath the aneurysm where turned up which led to the turbulent flow and mural thrombus formation. This finding emphasized the need for surgical treatment. A posterior access to the popliteal fossa was used. The peroperative findings were consistent with those of venous duplex imaging and ascending venography and also proved its close contact to the tibial nerve. The affected saphenous portion was resected un- 


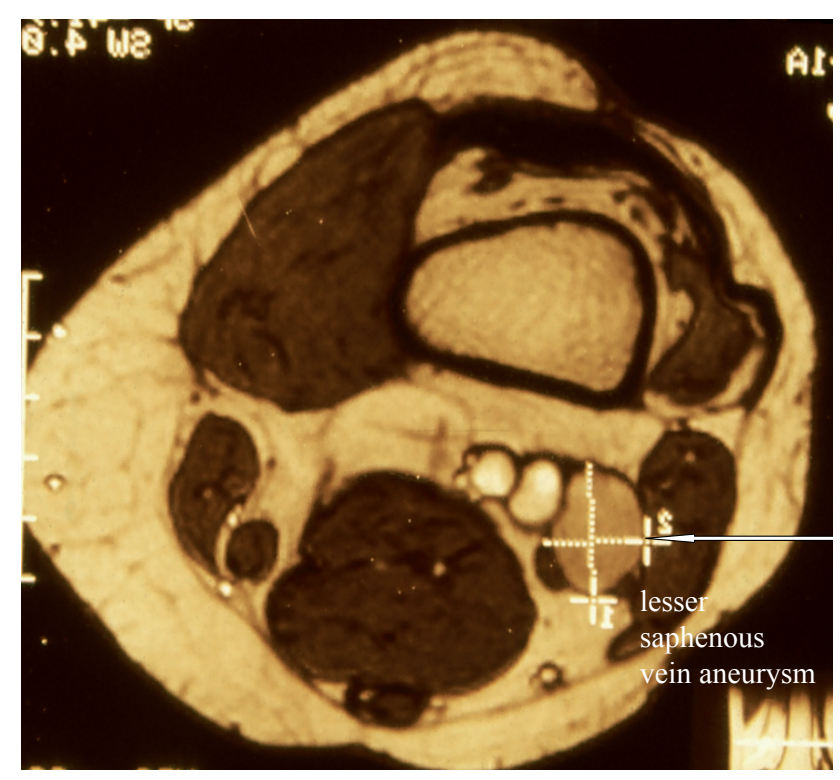

Fig. 1. Magnetic resonance imaging.

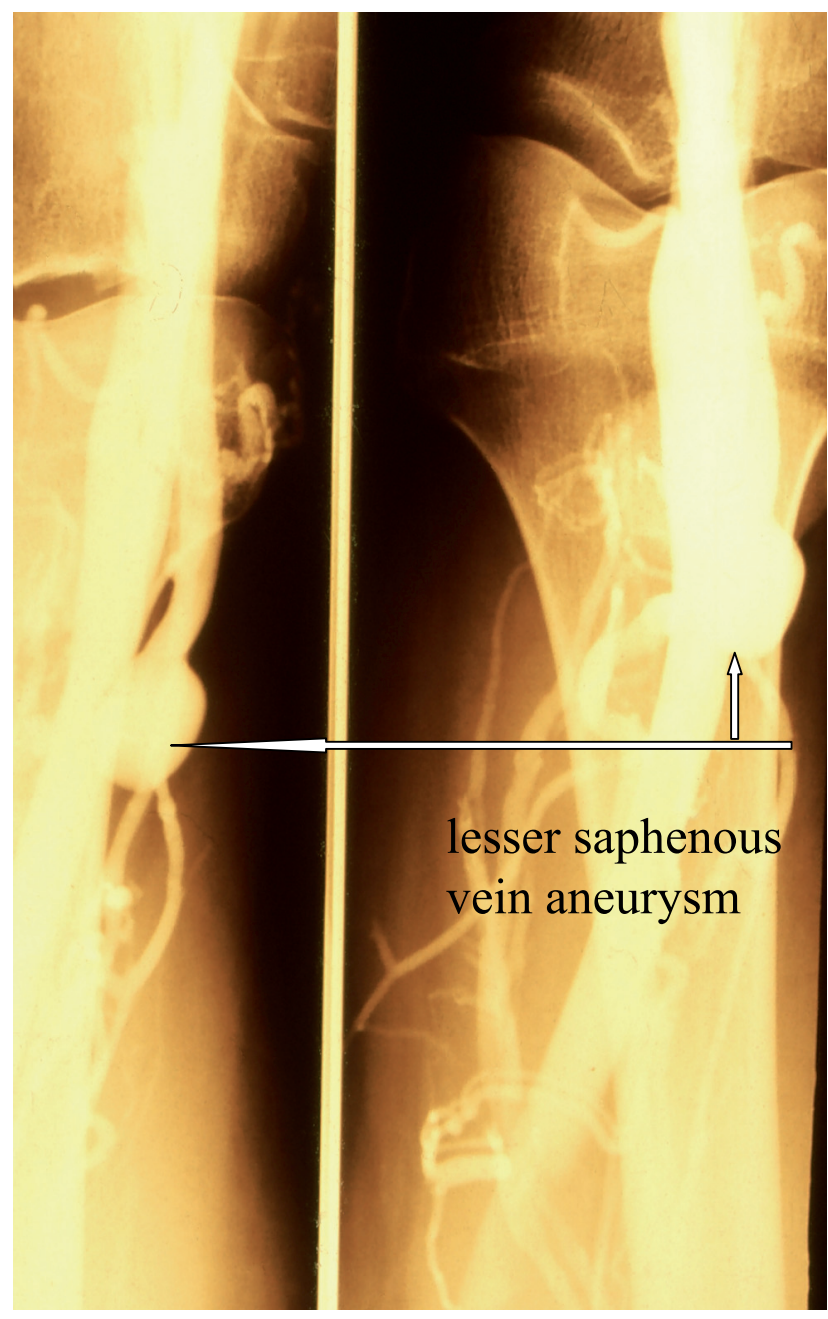

Fig. 2. Venography.

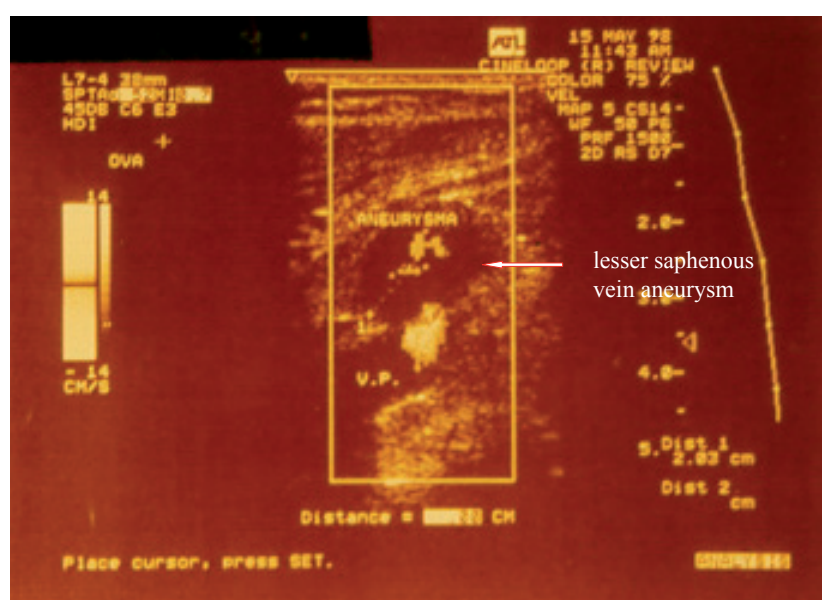

Fig. 3. Venous duplex imaging.

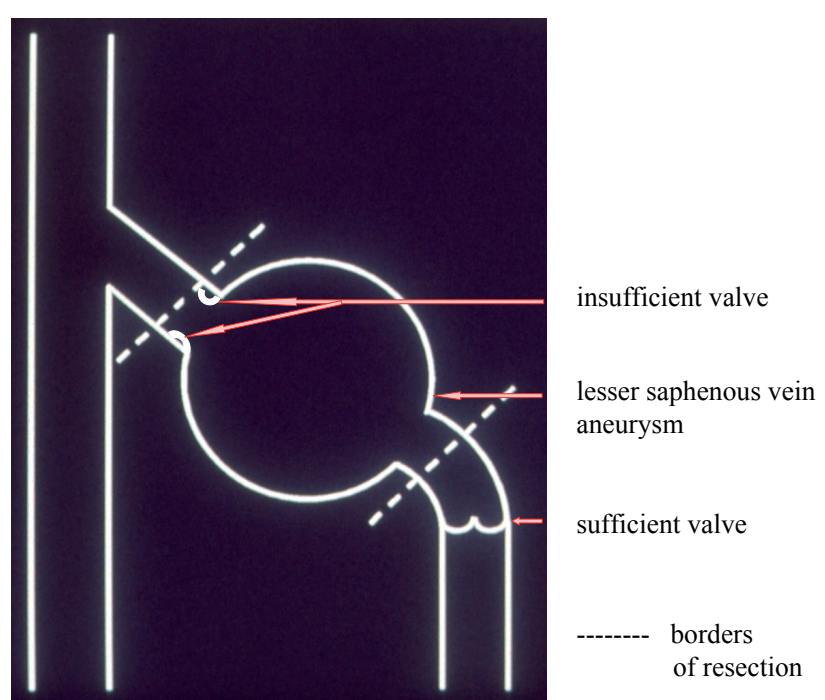

Fig. 4. Drawing of venous duplex imaging finding and drawing of resection.

der standard conditions of vascular surgery (ATB coverage, LMWH profylaxis perioperatively) (Fig. 5). The patient's postoperative course was free of complications; the complaints disappeared and she resumed her normal activities and returned to work. Because the surgery represented a conventional phlebectomy in fact, no antiaggregation or anticoagulation was given to the patient, but venotonics and elastic stocking were recommended. The histologic examination revealed all usual cell layers with intimal thickening and hyalinisation and medial attenuation consistent with endophlebosclerosis. An organizing mural thrombus was also seen. Ten years after the surgery the patient is still symptom-free and without venous duplex imaging evidence of a new venous aneurysm of lower limbs.

Case 2. A previously healthy 25-year-old woman was investigated for a slight intermittent dyscomfort in the left popliteal fossa. Physical examination of the lower limbs was negative. Venous duplex imaging revealed a $18 \mathrm{~mm}$ wide fusiforme popliteal vein aneurysm without any evi- 


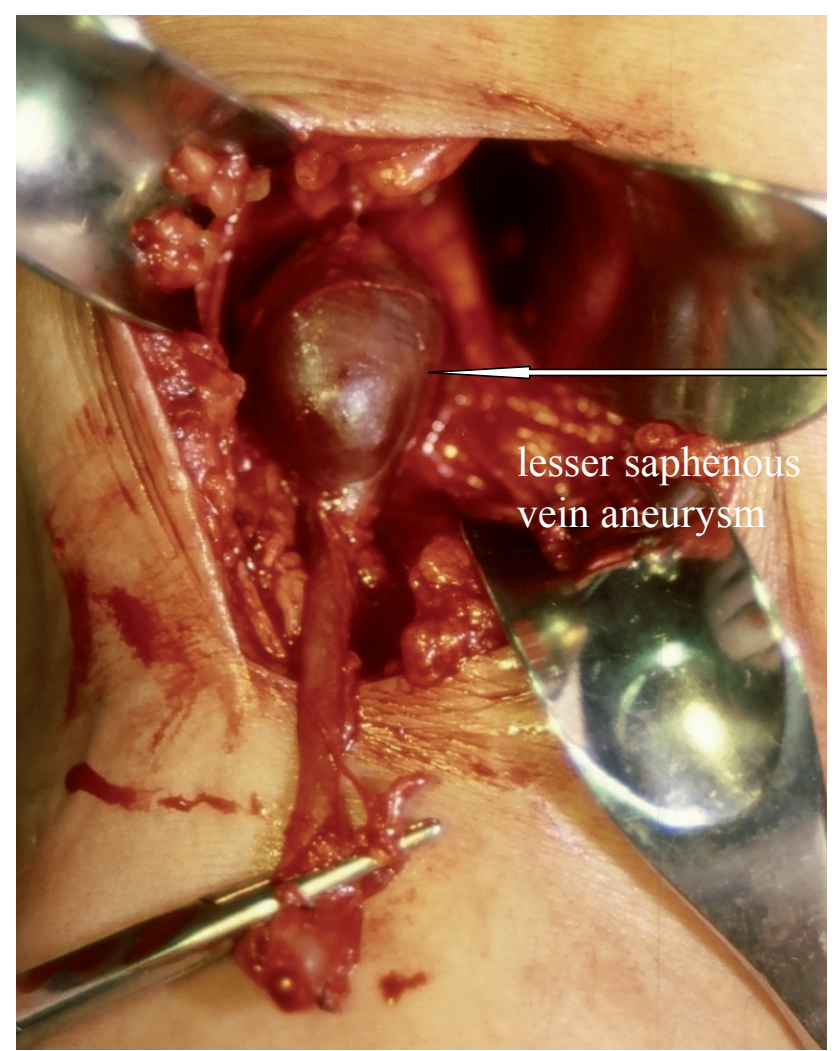

Fig. 5. Peroperative view.

dence of mural thrombus. No other significant pathology was found in the veins of both lower extremities. She agreed with conservative treatment only. Elastic stockings and regular venous duplex imaging follow up with surgical treatment in case of progression were recommended. Follow-up venous duplex imaging and her complaints after six, twelve and twenty-four months have been identical.

\section{LITERATURE REVIEW AND DISCUSSION}

The causes of venous aneurysms have been still unclear. They probably result from congenital and/or acquired (trauma, inflammation, degenerative changes, postthrombotic syndrome and also physiological stimulations e.g. cough) weakness of venous wall ${ }^{6-9}$. Although some authors reported no evident pathologic changes ${ }^{10}$ reports of others included a detailed microscopic description of the lesions called endophlebohypertrophy and endophlebosclerosis ${ }^{8,9,11-13}$, which was also found in the our case 1 . Some histologic features of these findings were described also in clearly congenital jugular venous aneurysm; it had been present at birth ${ }^{14}$. Therefore it seems that venous aneurysms may also arise in congenitally predisposed persons as a consequence of aquired mechanisms ${ }^{8}$. At the molecular level, increased expression of some matrix metalloproteinases in the wall of venous aneurysms suggests a possible causal role in their pathogenesis $^{13}$.

Venous aneurysms occur equally between the $\operatorname{exes}^{5,8}$ or with a slight female predominance ${ }^{15}$. They are seen in different age groups ${ }^{5,8,16}$, more often on the left lower $\operatorname{limb}^{15}$, bilateral occurrence is possible too ${ }^{4,5}$. Their most frequently used diagnostic test is venography, increasingly replaced by venous duplex imaging in recent years ${ }^{15,17}$.

They usually have these following modes of presentation: asymptomatic with incidental finding, local extremity symptoms and/or pulmonary embolism.

Local extremity symptoms are represented by pain, swelling or palpable mass (Greater saphenous vein aneurysm $^{3,18}$ and femoral vein aneurysm ${ }^{19}$ in the inguinal region can be misdiagnosed as inguinal or femoral hernia).

Increased use of venous duplex imaging in recent years in patients with chronic venous insufficiency leads to more frequent incidental discovery of both superficial ${ }^{4}$ and deep venous aneurysms ${ }^{20,21}$, nevertheless in majority of patients with deep, especially popliteal venous aneurysms, this presented with pulmonary emboli $2,7,8,15,22-26$. On the other hand, thrombembolism is less common in aneurysms involving superficial veins than those involving deep ones ${ }^{3-5}$. Our case 1 did not present with pulmonary emboli, nevertheless mural thrombus and turbulent blood flow and therefore risk of possible emboli were present. In available literature we have found one case of lesser saphenous vein aneurysm presenting as a popliteal mass ${ }^{27}$. Incidental findings of lesser saphenous vein aneurysm in patients with chronic venous insufficiency reported Pascarella ${ }^{4}$. There is no concensus on surgical treatment of superficial venous aneurysms. Calligaro et al. reserve it only if they are symptomatic, enlarging, or disfiguring ${ }^{28}$. Ekim et al. ${ }^{29}$ suggest surgery in all cases to prevent possible complications. Also in our opinion, surgical management of superficial venous aneurysms can be recommend in all but high-risk patients regarding it represents moreover usually very simple procedure e.i. resection of superficial vein.

Most deep venous aneurysms of the lower limbs are represented by popliteal venous aneurysms, on which the recommendation of surgical therapy is based. Turbulent blood flow in saccular aneurysms represents higher risk of mural thrombus formation and subsequent pulmonary emboli than rather linear blood flow in fusiform one, therefore some authors recommend close observation of small $(<20 \mathrm{~mm})$, asymptomatic, fusiform aneurysms, because their incidence of thromboembolic complications is low ${ }^{10}$. Similar recommendation Gobin presents, who has regard also to thrombus presence and considers permanent anticoagulation in some cases to be sufficient ${ }^{30}$. Our case 2 refused surgery . Having these pathological features of popliteal venous aneurysm, conservative procedure has been acceptable. Nevertheless, most authors recommend surgical repair of all popliteal venous aneurysms, which is based on these findings ${ }^{8,10,20,29,31}$ :

Pulmonary embolism was noted in more than $70 \%$ of cases $^{8,22,26}$ and high presence of the saccular, i.e. more dangerous, shape of aneurysm was also found ${ }^{8,20}$. No operated patient had subsequent pulmonary emboli and there were no operative deaths ${ }^{8,20,32}$. On the contrary, patients treated with anticoagulation without subsequent operative repair received recurrent pulmonary emboli ${ }^{8,10,33}$. Surgical 
treatment has been accompanied by a low morbidity and high patency rates (as high as $75 \%)^{8,32}$.

Tangencial aneurysmectomy with lateral venorrhaphy is the most frequent and popular operative technique in saccular aneurysms due to the exclusion endothelium injured by vascular clamp from the circulation. Resection with end-to-end anastomosis or with vein graft (usually saphenous) interposition represent other possibilities of surgery.

A new method with minimum invasiveness in the treatment of venous aneurysms was first presented by Cesarone et al. ${ }^{19}$, who reported a successful occlusion of a femoral venous aneurysm with foam-sclerotherapy. Simplicity and efficiency of sclerotherapy of superficial venous aneurysms were demonstrated by Seo et al. ${ }^{34}$.

\section{CONCLUSION}

Although being rare vascular abnormalities, venous aneurysms are increasingly found with the widespread use of venous duplex imaging, and questions have arisen as to their management.

Most superficial venous aneurysms are of little clinical significance, nevertheless some exceptions can be found. Since the surgical therapy is very simple, it can be recommended whenever possible. Deep venous aneurysms, especially popliteal ones, are more often a source of pulmonary emboli and their surgical therapy achieves good results. It is therefore recommended in all cases, but selective indication to surgery based on their pathological features and presentation is acceptable too.

\section{Abbreviations:}

PVA - Popliteal vein aneurysm

CTA - Computer tomography angiography

MRI - Magnetic resonance imaging

ATB - Antibiotics

LMWH - Low molecular weight heparin

\section{REFERENCES}

1. May R, Nissel R. Aneurysma der Vena poplitea. Rofo Fortschr Geb Rontgenstr Neuen Bildgeb Verfahr 1968; 108, 402-403.

2. Dahl JR, Freed TA, Burke MF. Popliteal vein aneurysm with recurrent pulmonary thromboemboli. JAMA 1976; 236, 2531-2532.

3. Akoudad H, Chaouki S, Cherti M, Benmimounm EG, Arharbi M. Aneurysm of the internal saphenous vein: report of a case. Ann Cardiol Angeiol (Paris) 2001; 50, 142-145.

4. Pascarella L, Al-Tuwaijri M, Bergan JJ, Mekenas LM. Lower extremity superficial venous aneurysms. Ann Vasc Surg 2005; 19, 69-73.

5. Gillespie DL, Villavicencio JL, Gallagher C, Chang A, Hamelink JK, Fiala LA, O'Donnell SD, Jackson MR, Pikoulis E, Rich NM. Presentation and management of venous aneurysms. J Vasc Surg 1997; 26, 845-852.

6. Friedman SG, Krishnasastry KV, Doscher W, Deckoff SL. Primary venous aneurysms. Surgery 1990; 108, 92-95.

7. Chahlaoui J, Julien M, Nadeau PU, Bruneau L, Roy P, Sylvestre J. Popliteal venous aneurysm: a source of pumonary embolism. Amer J Roentgenol 1981; 136, 415-416.
8. Aldridge SC, Comerota AJ, Katz ML, Wolk, JH, Goldman BI, White JV. Popliteal venous aneurysm: Report of two cases and review of the world literature. J Vasc Surg 1993; 18, 708-715.

9. Chatz IJ, Fine G. Venous aneurysms. N Engl J Med 1962; 266, 1310-1312.

10. Herrera LJ, Davis JW, Livesay JJ. Popliteal vein aneurysm presenting as popliteal mass. Tex Heart Inst J 2006; 33, 246-248.

11. Lev M, Saphir O. Endophlebohypertrophy ad phlebosclerosis. Arch Pathol 1951; 51, 154-178.

12. Bacciu PP, Porcu P, Marongiu GM. Popliteal vein aneurysms. Journal des Maladies Vasculaires 2000; 25, 360-365.

13. Irwin C, Synn A, Kraiss L, Zhang Q, Griffen MM, Hunter GC. Metalloproteinase expression in venous aneurysms. J Vasc Surg 2008; 48, 1278-1285.

14. Koh S, Brown RE, Hollabaugh RS. Venous aneurysm. South Med J 1984; 77, 1327-1328.

15. Bergqvist D, Bjorck M, Ljungman C. Popliteal venous aneurysm a systematic review. World Journal of Surgery 2006; 30, 273-279.

16. Greenwood LH, Yrizarry JM, Hallett JW Jr. Peripheral venous aneurysms with recurrent pulmonary embolism: report of a case and review of the literature 1982; 5, 43-45.

17. Symvoulakis EK, Klinis S, Peteinarakis D, Antonakis N, Tsafantakis $\mathrm{E}$, Lionis C. Diagnosing a popliteal venous aneurysm in a primary care setting: A case report. J Med Case Reports 2008; 22, 307.

18. Majeski J. Surgical repair of primary saphenous vein aneurysm of the proximal leg after initial presentation as an inguinal hernia. Am Surg 2002; 68, 999-1002.

19. Cesarone MR, Belcaro G, Nicolaides AN, Geroulakos G, Caciagli F, Cornelli U. Treatment of a femoral venous aneurysm with foamsclerotherapy. Minerva Cardioangiol 2003; 51, 405-409.

20. Sessa C, Nicolini P, Perrin M, Farah I, Magne JL, Guidicelli H. Management of symptomatic and asymptomatic popliteal venous aneurysms: a retrospective analysis of 25 patients and review of the literature. J Vasc Surg 2000; 32, 902-912.

21. Christenson JT. Popliteal venous aneurysm: a report on three cases presenting with chronic venous insufficiency without embolic events. Phlebology 2007; 22, 56-59.

22. Guex JJ. (im Druck) Anévrysmes de la veine poplitée: aspects cliniques. Phlébologie 50, 23-25.

23. Winchester D, Pearce WH, McCarthy WJ, McGee GS, Yao JS. Popliteal venous aneurysms. Surgery 1993; 114, 600-607.

24. Donald IP, Edwards RC. Fatal outcome from popliteal venous aneurysm associated with pulmonary embolism. Brit Radiol 1982; 55, 930-931.

25. Persson BG, Donner M, Petersson B, Wontzell K, Ellof B. Aneurysm of the popliteal vein as a cause of pulmonary embolism. Acta med scand 1980; 208, 407-410.

26. Ross GJ, Barber LW, Vujic I. Popliteal venous aneurysm. Radiology 1988; 168, 721-722.

27. Kim DH, Lescault EJ. Aneurysm of the small saphenous vein presenting as a popliteal mass: a case report. Am J Orthop 1999; 28, 304-305.

28. Calligaro KD, Ahmad S, Dandora R, Dougherty MJ, Savarese RP, Doerr KJ, McAffee S, De Laurentis DA. Venous aneurysms: surgical indications and review of the literature. Surgery 1995; 117, 1-6.

29. Ekim H, Kutay V, Tuncer M, Gultekin U. Management of primary venous aneurysms. Saudi Med J 2004; 25, 303-307.

30. Gobin JP, Grossetête C. Indications thérapeutiques dans les anévrysmes veineux poplités. Phlébologie 1997; 50, 61-66.

31. Nasr W, Babbitt R, Eslami MH. Popliteal vein aneurysm: a case report and review of literature. Vasc Endovascular Surg 2008; 41, 551-555.

32. Coffman SW, Leon SM, Gupta SK. Popliteal venous aneurysm: report of an unusual presentation and literatue review. Ann Vasc Surg 2000; 14, 286-290.

33. Russell DA, Robinson GJ, Johnson BF. Popliteal venous aneurysm: a rare cause of recurrent pulmonary emboli and limb swelling. Cardiovasc Intervent Radiol 2008; 31, 1026-1029.

34. Seo SH, Kim MB, Kwon KS, Kim CW, Oh CK. Primary venous aneurysms of the superficial venous system. Angiology 2008; 59, 593-598. 